\title{
ANNUAL INCIDENCE AND CLINICO-LABORATORY STUDY OF HEMOLYTIC UREMIC SYNDROME AMONG ATTENDANTS OF PEDIATRIC ZAGAZIG UNIVERSITY HOSPITAL.
}

\author{
Samir Mohammed Zamzam ${ }^{1}$, Ali Abdel Hameed ${ }^{1}$, Naglaa Ali Khalifa ${ }^{2}$, Sabry Abdel Rahman Tolba ${ }^{1}$. \\ Pediatrics ${ }^{l}$ and Clinical Pathology ${ }^{2}$ Departments, faculty of medicine, Zagazig university, Egypt.
}

Corresponding
Author:
Sabry Abdel Rahman
Tolba.
Tel: 01013176062
Email:sabryelshobary
@ gmail.com

\section{ABSTRACT}

Background: Hemolytic uremic syndrome (HUS) is the most common cause of acute renal failure in young children. It is characterized by microangiopathic hemolytic anemia (MAHA), acute renal failure, and thrombocytopenia.

Objective: This work aims to study causes, clinical presentation, annual incidence, and outcome of hemolytic uremic syndrome in children admitted to Pediatric Zagazig University Hospital.

Subjects and methods: This is a descriptive study, carried out at Children hospital, faculty of medicine, Zagazig University during the period from January 2012 to January 2014.This study included 42 patients younger than 15 years with diagnosis of hemolytic uremic syndrome.

Results: Most of cases were younger than 2 years of age (57\%). Males (74\%) were more affected than females $(26 \%)$ and most of patients were detected during summer. The overall incidence in pediatric age group ( $<15$ years) was 1.2 per 100,000 children. Incidence was highest below 5 years old $(2.69$ per 100,000 children). Most of patients were presented clinically by bloody diarrhea, pallor, oliguria \& anuria. Laboratory abnormalities included hemolytic anemia, thrombocytopenia, leukocytosis, hyponatremia, hypokalemia or hyperkalemia, metabolic acidosis, elevated blood urea and serum creatinine. Stool culture was positive in only 7 cases (17\%).The mortality rate was $21.4 \%$.

Conclusion: Unfavorable outcome was associated with young age, anuria, intractable seizures, high WBC count more than 30,000 per mm 3 , and hyperkalemia above $5 \mathrm{~m} \mathrm{~mol} / \mathrm{L}$.

Key words: Hemolytic Uremic Syndrome, Shiga-toxin, Acute Kidney Injury, Hemodialysis, Complement, TMA, MAHA.

\section{INTRODUCTION}

H emolytic uremic syndrome (HUS) is diagnosed by combination of microangiopathic hemolytic anemia (MAHA), acute renal failure, and thrombocytopenia. It is the most common cause of acute renal failure in children ${ }^{[1]}$. The main histopathological feature is thrombotic microangiopathy (TMA), characterized by endothelial damage and formation of plugs containing platelet and fibrin. This induces ischemia, RBCs damage, and c thrombocytopenia ${ }^{[2]}$. HUS is classified into two types according to presence or absence preceding diarrhea. Diarrhea positive (typical) HUS and diarrhea negative (atypical) HUS ${ }^{[3] .}$ Typical HUS (tHUS) is mainly caused by enterohemorrhagic E-coli (EHEC) infection or shigella desentriae type 1 infection [4]. Atypical HUS (aHUS) is mainly caused by other infections, complement factor abnormalities, drug exposure, malignancy, irradiation, or systemic lupus erythematosus [5].

The main features of HUS include microangiopathic hemolytic anemia (MAHA), thrombocytopenia, and acute renal failure. Peripheral blood smears reveal the presence of MAHA by fragmented RBCs (schistocytes, burr cells and helmet cells). The degree of renal involvement varies and determines the increase in blood urea, creatinine, potassium and phosphate ${ }^{[6]}$. The aim of this work is to study causes, clinical presentation, annual incidence, and outcome of hemolytic uremic syndrome in children admitted to Pediatric Zagazig University Hospital.

\section{SUBJECTS AND METHODS}

This is a descriptive study, carried out at Children hospital, faculty of medicine, Zagazig University during the period from January 2012 to January 2014.This study included 42 patients younger than 15 years with diagnosis of hemolytic uremic 
syndrome. Informed consent was taken from parents or care-givers of children to be enrolled in the study. The study was approved by the ethical committee of faculty medicine, Zagazig University.

Inclusion criteria: Any patient who was presented with three or more of the following: 1. Anuria or oliguria lasting for more than 24 hours with elevated urea and creatinine level.

2. Features of hemolytic anemia with hemoglobin less than $10 \mathrm{~g} / \mathrm{dl}$.

3. Low platelet count less than $100000 / \mathrm{mm} 3$.

4. Past history of preceding bloody diarrhea.

Exclusion criteria: Exclusion criteria included infants and children with any condition or disease state which may cause impaired kidney function and anemia without fulfilling the diagnostic criteria of hemolytic uremic syndrome including

- Disseminated

intravascular

coagulopathy (DIC).

- Septicemia.

- Bilateral renal vein thrombosis.

- Chronic renal failure.

- Chronic hemolytic anemia.

- Tumor lysis syndrome.

- Children taking nephrotoxic drugs

\section{Methods:}

All children included in this study were subjected to full history taking, thorough clinical examination, laboratory investigations in the form of CBC (complete blood count), reticulocytic count, peripheral blood smear for features of hemolysis, Coombs' test, kidney and liver function tests, PT (prothrombin time), PTT (partial thromboblastin time), routine stool analysis (physical and microscopic examination), stool culture, routine urine analysis urine culture, arterial blood gas analysis (ABG), blood glucose level, serum sodium, and serum potassium, blood culture, complement (C3) concentration, anti-nuclear antibody (ANA) titre, Anti-ds-DNA antibody titre, hepatitis B surface antigen ( $\mathrm{HBs} \mathrm{Ag}$ ), hepatitis $\mathrm{C}$ virus antibody (HCV-Ab). Radiological investigations in the form of plain chest radiography and pelvi-abdominal ultrasonography were done also for all patients. As regard treatment given to our patients, 37 patients $(88 \%)$ received packed RBCs transfusion. Plasma infusion $10 \mathrm{mg} / \mathrm{kg}$ twice daily was given to 41 patients $(98 \%)$ for 5-14 days. 36 patients $(86 \%)$ were subjected to hemodialysis for $2-14$ sessions. Antibiotics were avoided specially in patients with history of diarrhea.

\section{STATISTICAL ANALYSIS}

Data collected throughout history, basic clinical examination, laboratory investigations and outcome measures coded, entered and analyzed using Microsoft Excel software. Data were then imported into Statistical Package for the Social Sciences (SPSS version 20.0) software for analysis. According to the type of data qualitative represent as number and percentage, quantitative continous group represent by mean $\pm S D$, the following tests were used to test differences for significance. Differences between frequencies (qualitative variables) and percentages in groups were compared by Chi-square test. $\mathbf{P}$ value was set at $<0.05$ for statistically significant (s) results \& $\mathrm{P}$ value $<0.001$ for highly statistically significant (HS) result. $\mathrm{P}$ value $>0.05$ was considered as nonstatistically significant (NS). Data were collected and submitted to statistical analysis .

\section{RESULTS}

The study was performed at the nephrology unit and intensive care unit, Children hospital, Pediatrics and Clinical Pathology departments, faculty of medicine, Zagazig University during the period from January 2012 to January 2014 . Forty two children who were diagnosed as HUS were included in the present study.

Table (1) shows the annual incidence and age specific incidence of hemolytic uremic syndrome of children.

\begin{tabular}{lccc}
\hline Age & Number of cases per year & $\begin{array}{c}\text { Number of children } \\
\text { at risk }\end{array}$ & $\begin{array}{c}\text { Incidence per 100000 } \\
\text { children }\end{array}$ \\
\hline$<15$ years & 21 & 1755674 & 1.2 \\
\hline$<5$ years & 16 & 594568 & 2.69 \\
\hline $5-10$ years & 3 & 581689 & 0.516 \\
\hline $10-15$ years & 2 & 579417 & 0.35 \\
\hline
\end{tabular}


The overall incidence of hemolytic uremic syndrome of children in pediatric age group ( $<15$ years) was 1.2 per 100000 children. The annual incidence of HUS was highest below 5 years old $(2.69$ per 100000 children).

Table (2) Demographic picture of Hemolytic uremic syndrome ( $\mathrm{N}=42)$

\begin{tabular}{lll}
\hline Parameter & Frequency & Percent (\%) \\
\hline Age (years) & 3 & 7 \\
<1 year & 21 & 50 \\
From 1 year to < 2 years & 8 & 19 \\
From 2 years to < 5 years & 6 & 14 \\
From 5 years to < 10 years & 4 & 10 \\
$\quad$ From 10 years to < 15 years & & \\
\hline Sex & 31 & 74 \\
Male & 11 & 26 \\
Female & & 50 \\
\hline Season & 21 & 29 \\
From April to June & 12 & 7 \\
From July to September & 3 & 14 \\
From October to December & 6 & \\
From January to March & & \\
\hline
\end{tabular}

Most of cases were younger than 2 years of age (57\%). Males (74\%) were more affected than females $(26 \%)$ and most of patients were detected during summer.

Table (3) Clinical manifestations of hemolytic uremic syndrome (N=42).

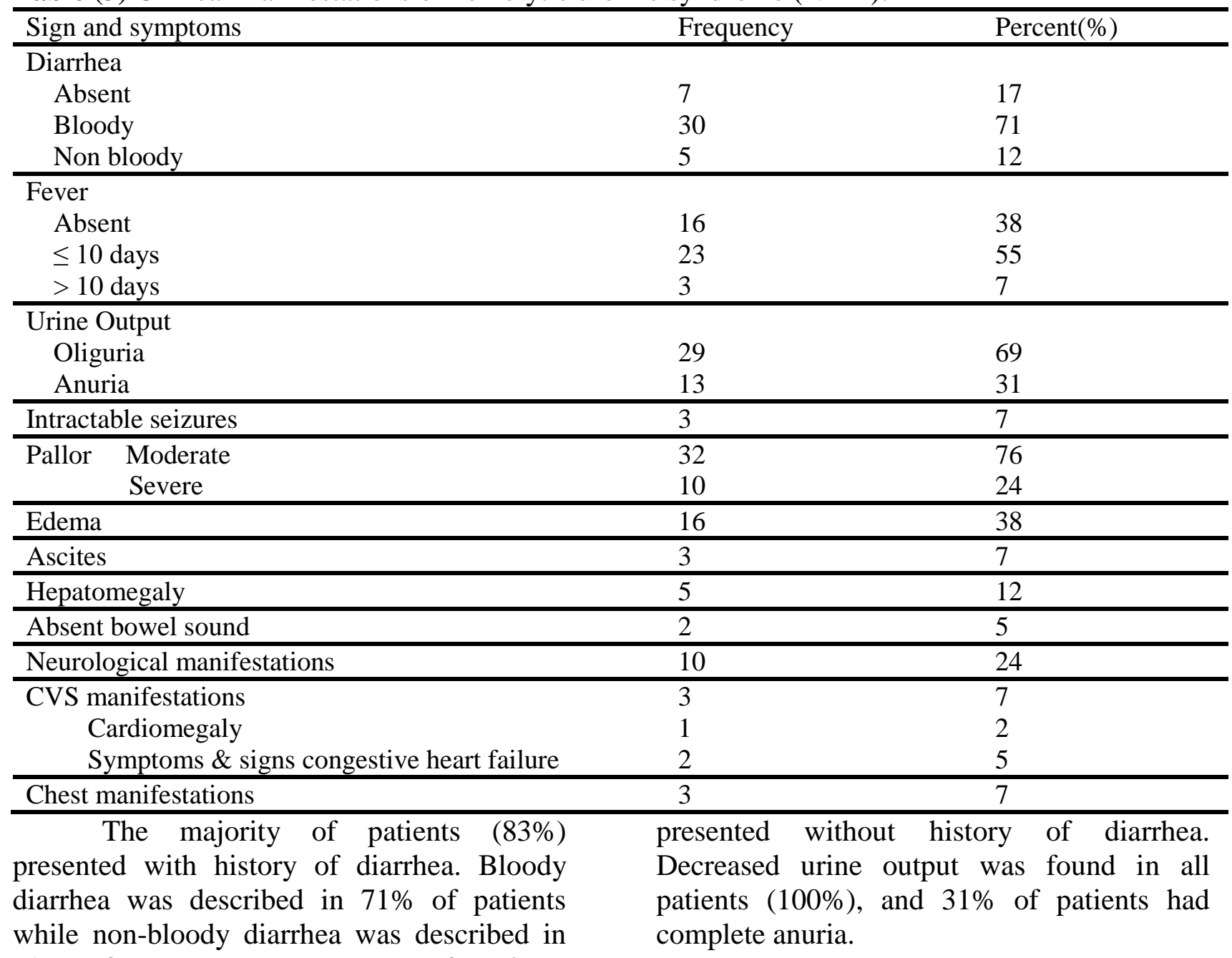

$12 \%$ of cases. However $17 \%$ of patients 
About $7 \%$ of patients presented with intractable generalized convulsions. All the patients presented with pallor which was severe in $10(24 \%)$ patients. $38 \%$ of patients presented with edema. We noticed ascites in $7 \%$ patients, hepatomegaly in $12 \%$ of cases and absent bowel sounds in $5 \%$ of patients.

Neurological manifestations as headache, convulsions, disturbed conscious level and irritability were present in 10 (24\%) patients. Chest examination revealed diminished air entry and crepitations in 3 (7\%) patients. Cardiovascular system manifestations were found in $3(7 \%)$ cases. One patient showed cardiomegaly and two patients showed signs and symptoms of congestive cardiac failure.

Table (4) Hematological Abnormalities of HUS patients (N=42).

\begin{tabular}{llll}
\hline Parameter & Frequency & $\begin{array}{l}\text { Percent } \\
(\%)\end{array}$ & Mean \pm 1 SD (Range) \\
\hline TLC & 14 & 33 & $18021 \pm 13050$ (4100 -35000) \\
$<15000 / \mathrm{mm} 3$ & 18 & 43 & \\
15000 & $30000 / \mathrm{mm} 3$ & 24 & \\
$>30000 / \mathrm{mm} 3$ & 10 & & $84600 \pm 51600$ (13500-30400) \\
\hline Platelet count & 9 & 21 & \\
$<50000 / \mathrm{mm} 3$ & 24 & 57 & \\
$50000-100000 / \mathrm{mm} 3$ & 9 & 21 & \\
$>100000 / \mathrm{mm} 3$ & & & $6.7 \pm 1.9(4.3-9.2)$ \\
\hline Hemoglobin (g/dL) & 9 & 21 & \\
$<5$ & 28 & 67 & \\
$5-8$ & 5 & 12 & \\
$>8$ & 42 & 100 & $2.25 \pm 1.3(0.7-7.2)$ \\
\hline Reticulocytosis & 42 & 100 & \\
\hline Features of hemolysis in blood film & 42 & 100 & \\
\hline Negative direct Coombs test & 3 & 7 & \\
\hline Positive blood culture & 42 & 100 & \\
\hline Normal prothrombin time (PT) & and & 42 & \\
partial thromboplastin time (PTT). & & & \\
\hline
\end{tabular}

Leukocytosis (> 15000/mm3) was found in $67 \%$ cases. The platelet count range from 13500 to 30400 with mean count as 84600 per $\mathrm{mm} 3$. Nine patients $(21 \%)$ had platelet count less than 50000 per mm3. Nine patients $(21 \%)$ had severe anemia $(<5 \mathrm{~g} / \mathrm{dL})$ and the mean hemoglobin was $6.7 \mathrm{~g} / \mathrm{dL}$ and range of hemoglobin level was from 4.3 to 9.2 $\mathrm{g} / \mathrm{dL}$. The mean reticulocytic count was $2.25 \%$. Direct Coombs test was negative in all cases (100\%) and blood film showed fragmented RBCs in all cases (100\%). Positive blood culture was noticed only in three patients $(7 \%)$; pseudomonas aeruginosa in one case, Streptococcus pneumoniae in the second, and klebsilla pneumoniae in the third case. All patients had normal PT (prothrombin time) and PTT (partial thromboplastin time). 
Table (5) Biochemical abnormalities of HUS patients ( $\mathrm{N}=42)$.

\begin{tabular}{|c|c|c|c|}
\hline Parameter & Frequency & $\begin{array}{l}\text { Percent } \\
(\%)\end{array}$ & Mean \pm SD (range) \\
\hline $\begin{array}{l}\text { Sodium }(\mathrm{m} \mathrm{mol} / \mathrm{L}) \\
\quad<135 \\
135-145 \\
>145 \\
\end{array}$ & $\begin{array}{l}38 \\
3 \\
1 \\
\end{array}$ & $\begin{array}{l}91 \\
7 \\
2 \\
\end{array}$ & $\begin{array}{l}126.6 \pm 9.5 \\
(107-161)\end{array}$ \\
\hline $\begin{array}{l}\text { Potassium }(\mathrm{m} \mathrm{mol} / \mathrm{L}) \\
\quad<3.5 \\
3.5-5 \\
>5\end{array}$ & $\begin{array}{l}19 \\
12 \\
11\end{array}$ & $\begin{array}{l}45 \\
29 \\
26\end{array}$ & $\begin{array}{l}4.12 \pm 1.58 \\
(2.1-8.7)\end{array}$ \\
\hline Low bicarbonate level (m mol/L) & 28 & 67 & $\begin{array}{l}12.45 \pm 3.97 \\
(6.5-20.6)\end{array}$ \\
\hline Low PH & 28 & 67 & $\begin{array}{l}7.31 \pm 0.06 \\
(7.21-7.42)\end{array}$ \\
\hline $\begin{array}{l}\text { Creatinine (mg/dL) } \\
\begin{array}{l}1-3 \\
3-5 \\
>5\end{array}\end{array}$ & $\begin{array}{l}12 \\
19 \\
11\end{array}$ & $\begin{array}{l}29 \\
45 \\
26\end{array}$ & $\begin{array}{l}2.51 \pm 1.59 \\
(1.1-5.8)\end{array}$ \\
\hline $\begin{array}{l}\text { Urea }(\mathrm{mg} / \mathrm{dL}) \\
50-100 \\
100-150 \\
>150\end{array}$ & $\begin{array}{l}6 \\
10 \\
26\end{array}$ & $\begin{array}{l}14 \\
24 \\
62\end{array}$ & $\begin{array}{l}113.7 \pm 45.2 \\
(56-187)\end{array}$ \\
\hline
\end{tabular}

$91 \%$ of patients had hyponatremia and only $2 \%$ of patients had hypernatremia . Also, $45 \%$ of cases had hypokalemia and $26 \%$ of cases had hyperkalemia. Metabolic acidosis with low $\mathrm{PH}$ and low bicarbonate was observed in 28 cases $(67 \%)$. High serum creatinine level above $1 \mathrm{mg} / \mathrm{dL}$ was noticed in all cases $(100 \%)$ and was higher than $5 \mathrm{mg} / \mathrm{dl}$ in $26 \%$ of cases. All patients $(100 \%)$ showed high blood urea level, and in $62 \%$ cases, the blood urea was above $150 \mathrm{mg} / \mathrm{dL}$.

Table (6) Stool examination of Hemolytic Uremic Syndrome patients (N=42).

\begin{tabular}{lll}
\hline Parameter & Frequency & Percent $(\%)$ \\
\hline Routine examination & 20 & \\
Normal stool exam. & 4 & 47 \\
RBCs > 5/HPF & 6 & 9 \\
Pus cells > 5/HPF & 5 & 14 \\
Entamaeba Histolytica cysts & 7 & 12 \\
Giardia Lamblia cysts & 7 & 17 \\
\hline Positive stool culure & 2 & 5 \\
Klebsilla pneumoniae & 1 & 2.4 \\
Shigella & 1 & 2.4 \\
Pseudomonas aeruginosa & 1 & 2.4 \\
Enterobacter & 1 & 2.4 \\
Acenitobacter baumanii & 1 & 2.4 \\
Candida. & & \\
\hline
\end{tabular}

In routine stool examination, $\mathrm{RBCs}$ were found in 4 cases (9\%), and pus cells were detected in 6 cases $(14 \%)$. We noticed entamaeba histolytica cysts in 5 patients $(12 \%)$ and giardia lamblia cysts in 7 patient
$(16 \%)$. Routine stool examination was normal in 20 patients $(47 \%)$. Stool culture was positive in only 7 cases (17\%); Klebsilla pneumoniae in 2 cases, Shigella in one case, Pseudomonas aeruginosa in one case, 
Enterobacter in one case, Acenitobacter baumanii in one case, and in one case Candida was grown.

In urine examination, significant albuminuria $(>++)$ was found in 5 cases $(12 \%)$, while mild proteinuria was detected in 16 cases $(38 \%)$. We found microscopic hematuria ( $>5 \mathrm{RBCs} / \mathrm{HPF}$ ) in 20 cases (48\%) and pyuria (> 5 pus cells/ HPF) in 6 cases (14\%). In 3 patients (7\%), we detected epithelial cells and in 2 patients (5\%), we observed granular casts. Positive urine culture was found in 2 cases (5\%); E. coli in one case, and klebsilla pneumoniae in the other.

C3 level was low in 9 cases $(21 \%)$, while C3 level was normal in 33 cases (79\%). Antinuclear antibody level (ANA) and Antids-DNA titre were negative in all patients
(100\%). Hepatitis markers (HBs Ag and HCV $\mathrm{Ab})$ were also negative in all patients $(100 \%)$.

As regard treatment given to our patients, 37 patients $(88 \%)$ received packed RBCs transfusion. Also, plasma infusion 10 $\mathrm{mg} / \mathrm{kg}$ twice daily was given to 41 patients (98\%) for 5-14 days. Only one case that was suspected to have pneumococcal HUS did not receive plasma infusion. 36 patients $(86 \%)$ were subjected to hemodialysis for $2-14$ sessions. Five patients (12\%) improved without the need for dialysis and one patient (2\%) died before initiation of dialysis. Antibiotics were avoided specially in patients with history of diarrhea. However, 26 cases $(62 \%)$ had history of antibiotic treatment before admission to our hospital either in outpatient clinic or in secondary hospital before diagnosis and referral.

Table (7) Outcome distribution among studied group of hemolytic uremic syndrome patients.

\begin{tabular}{|c|c|c|c|c|}
\hline & & & Frequency & Percent \\
\hline \multirow[t]{4}{*}{ Outcome } & \multicolumn{2}{|c|}{ Complete recovery } & 30 & 71.4 \\
\hline & \multirow{2}{*}{$\begin{array}{l}\text { Chronic } \\
\text { kidney } \\
\text { disease } \\
\text { (CKD) }\end{array}$} & $\begin{array}{l}\text { Necessitating } \\
\text { dialysis (ESRD) }\end{array}$ & 1 & 2.4 \\
\hline & & $\begin{array}{l}\text { Not } \\
\text { necessitating } \\
\text { dialysis }\end{array}$ & 2 & 4.8 \\
\hline & \multicolumn{2}{|l|}{ Death } & 9 & 21.4 \\
\hline \multirow[t]{2}{*}{ Outcome } & \multicolumn{2}{|l|}{$\mathrm{Bad}$} & 12 & 28.6 \\
\hline & \multicolumn{2}{|l|}{ Favorable } & 30 & 71.4 \\
\hline \multirow[t]{3}{*}{ Survival } & \multicolumn{2}{|l|}{ Survived } & 33 & 78.6 \\
\hline & \multicolumn{2}{|l|}{ Died } & 9 & 21.4 \\
\hline & \multicolumn{2}{|l|}{ Total } & 42 & 100.0 \\
\hline
\end{tabular}

Out of 42 patients, 30 patients $(71.4 \%)$ improved completely However, recurrence was documented in two cases who had complete recovery. Three patients $(7.2 \%)$ developed chronic kidney disease (CKD). One of them $(2.4 \%)$ developed end stage renal disease (ESRD) and became dialysis dependent, while two patients (4.8\%) developed mild impairment of kidney functions with hypertension and persistent microscopic hematuria (not necessitating dialysis). Mortality rate was $21.4 \%$ (nine patients). 
Table (8) showing comparison between favorable and unfavorable outcome of hemolytic uremic syndrome patients.

\begin{tabular}{|c|c|c|c|c|c|c|}
\hline & Outcome & $\mathrm{N}$ & Mean & $\begin{array}{l}\text { Std. } \\
\text { Deviation }\end{array}$ & $\mathrm{t} / \mathrm{MW}$ & $\mathrm{P}$ \\
\hline \multirow[t]{2}{*}{ Age } & Favorable & 30 & 4.6747 & 3.42568 & 2.394 & $0.021 *$ \\
\hline & Unfavorable & 12 & 2.1667 & 1.81175 & & \\
\hline \multirow[t]{2}{*}{$\mathrm{HB}$} & Favorable & 30 & 6.3533 & .97900 & 1.527 & 0.135 \\
\hline & Unfavorable & 12 & 5.7333 & 1.61546 & & \\
\hline \multirow[t]{2}{*}{ WBC } & Favorable & 30 & 13.9600 & 3.42220 & -14.384 & $0.00 * *$ \\
\hline & Unfavorable & 12 & 31.4417 & 3.89369 & & \\
\hline \multirow[t]{2}{*}{ Platelet } & Favorable & 30 & 93.1667 & 20.43000 & 6.909 & $0.00 * *$ \\
\hline & Unfavorable & 12 & 47.2500 & 16.62487 & & \\
\hline \multirow{2}{*}{$\begin{array}{l}\text { Reticulocytic } \\
\text { count }\end{array}$} & Favorable & 30 & 5.8867 & 4.36473 & -0.375 & 0.710 \\
\hline & Unfavorable & 12 & 6.4417 & 4.24038 & & \\
\hline \multirow[t]{2}{*}{ Urea } & Favorable & 30 & 160.6000 & 48.62425 & -7.082 & $0.00 * *$ \\
\hline & Unfavorable & 12 & 267.4167 & 29.28685 & & \\
\hline \multirow[t]{2}{*}{ Creatinine } & Favorable & 30 & 3.5933 & 1.18494 & -6.013 & $0.00 * *$ \\
\hline & Unfavorable & 12 & 6.0167 & 1.16684 & & \\
\hline \multirow[t]{2}{*}{ PT } & Favorable & 30 & 11.6833 & .70078 & -0.735 & 0.466 \\
\hline & Unfavorable & 12 & 11.8500 & .55350 & & \\
\hline \multirow[t]{2}{*}{ PTT } & Favorable & 30 & 34.2667 & 2.24274 & 0.681 & 0.500 \\
\hline & Unfavorable & 12 & 33.5833 & 4.25245 & & \\
\hline \multirow[t]{2}{*}{$\mathrm{C} 3$} & Favorable & 30 & 107.2333 & 21.23381 & 0.246 & 0.807 \\
\hline & Unfavorable & 12 & 105.4167 & 22.73347 & & \\
\hline \multirow[t]{2}{*}{$\mathrm{PH}$} & Favorable & 30 & 7.3027 & .07017 & 6.405 & $0.00 * *$ \\
\hline & Unfavorable & 12 & 7.1542 & .06142 & & \\
\hline \multirow[t]{2}{*}{ NA } & Favorable & 30 & 132.4667 & 4.79751 & 0.604 & 0.550 \\
\hline & Unfavorable & 12 & 130.8333 & 12.94628 & & \\
\hline \multirow[t]{2}{*}{ K } & Favorable & 30 & 3.4633 & .73835 & -6.824 & $0.00 * *$ \\
\hline & Unfavorable & 12 & 5.2083 & .77513 & & \\
\hline
\end{tabular}

Unfavorable outcome was associated with young age ( $\mathrm{P}$ value $<0.05)$, high $\mathrm{WBC}$ count more than 30000 per $\mathrm{mm} 3$ ( $\mathrm{P}$ value $<0.001$ ), low platelet count less than 50000/mm3 ( $\mathrm{P}$ value $<0.001$ ), high blood urea above $250 \mathrm{mg} / \mathrm{dl}$ (P value < 0.001), high serum creatinine above 5mg/dl (P value $<0.001)$, low $\mathrm{PH}$ of the blood $<$ 7.2 ( $\mathrm{P}$ value $<0.001$ ), and hyperkalemia above $5 \mathrm{~m} \mathrm{~mol} / \mathrm{L}(\mathrm{P}$ value $<0.001)$. 
Table (9) showing association between outcome and other parameters

Outcome Total $\quad \mathrm{X}^{2} \quad \mathrm{P}$

\begin{tabular}{|c|c|c|c|c|c|c|c|}
\hline & & & \multirow{2}{*}{\multicolumn{2}{|c|}{ Unfavorable $\quad$ Favorable }} & & & \\
\hline & & & & & & & \\
\hline \multirow[t]{4}{*}{ Diarrhea } & \multirow[t]{2}{*}{$\mathrm{NO}$} & Count & $\begin{array}{r}0 \\
\end{array}$ & 7 & 7 & 3.36 & 0.06 \\
\hline & & $\%$ & $0.0 \%$ & $23.3 \%$ & $16.7 \%$ & & \\
\hline & \multirow[t]{2}{*}{ YES } & Count & 12 & 23 & 35 & & \\
\hline & & $\%$ & $100.0 \%$ & $76.7 \%$ & $83.3 \%$ & & \\
\hline \multirow[t]{4}{*}{ Anuria } & \multirow[t]{2}{*}{$\mathrm{NO}$} & Count & 2 & 27 & 29 & 21.5 & $0.00 * *$ \\
\hline & & $\%$ & $16.7 \%$ & $90.0 \%$ & $69.0 \%$ & & \\
\hline & \multirow[t]{2}{*}{ YES } & Count & 10 & 3 & 13 & & \\
\hline & & $\%$ & $83.3 \%$ & $10.0 \%$ & $31.0 \%$ & & \\
\hline \multirow{4}{*}{$\begin{array}{l}\text { Intractable } \\
\text { seizures }\end{array}$} & \multirow[t]{2}{*}{$-\mathrm{VE}$} & Count & 9 & 30 & 39 & 8.07 & 0.004* \\
\hline & & $\%$ & $75.0 \%$ & $100.0 \%$ & $92.9 \%$ & & \\
\hline & \multirow[t]{2}{*}{$+\mathrm{VE}$} & Count & 3 & $\mathbf{0}$ & 3 & & \\
\hline & & $\%$ & $25.0 \%$ & $0.0 \%$ & $7.1 \%$ & & \\
\hline \multirow[t]{4}{*}{ Urine culture } & \multirow[t]{2}{*}{$-\mathrm{VE}$} & Count & 12 & 28 & 40 & 0.84 & 0.35 \\
\hline & & $\%$ & $100.0 \%$ & $93.3 \%$ & $95.2 \%$ & & \\
\hline & \multirow[t]{2}{*}{$+\mathrm{VE}$} & Count & 0 & 2 & 2 & & \\
\hline & & $\%$ & $0.0 \%$ & $6.7 \%$ & $4.8 \%$ & & \\
\hline \multirow[t]{4}{*}{ Stool analysis } & \multirow[t]{2}{*}{$+\mathrm{VE}$} & Count & 4 & 14 & 18 & 0.62 & 0.43 \\
\hline & & $\%$ & $33.3 \%$ & $46.7 \%$ & $42.9 \%$ & & \\
\hline & \multirow[t]{2}{*}{$-\mathrm{VE}$} & Count & 8 & 16 & 24 & & \\
\hline & & $\%$ & $66.7 \%$ & $53.3 \%$ & $57.1 \%$ & & \\
\hline Stool culture & $-\mathrm{VE}$ & Count & 11 & 24 & 35 & 0.84 & 0.35 \\
\hline & & $\%$ & $91.7 \%$ & $80.0 \%$ & $83.3 \%$ & & \\
\hline & $+\mathrm{VE}$ & Count & 1 & 6 & 7 & & \\
\hline & & $\%$ & $8.3 \%$ & $20.0 \%$ & $16.7 \%$ & & \\
\hline Blood culture & $-\mathrm{VE}$ & Count & 9 & 30 & 39 & 8.07 & 0.004* \\
\hline & & $\%$ & $75.0 \%$ & $100.0 \%$ & $92.9 \%$ & & \\
\hline & $+\mathrm{VE}$ & Count & 3 & $\mathbf{0}$ & 3 & & \\
\hline & & $\%$ & $25.0 \%$ & $0.0 \%$ & $7.1 \%$ & & \\
\hline Low C3 & $\mathrm{NO}$ & Count & 10 & 23 & 33 & 0.22 & 0.63 \\
\hline & & $\%$ & $83.3 \%$ & $76.7 \%$ & $78.6 \%$ & & \\
\hline & YES & Count & 2 & 7 & 9 & & \\
\hline & & $\%$ & $16.7 \%$ & $23.3 \%$ & $21.4 \%$ & & \\
\hline Packed RBCs & $-\mathrm{VE}$ & Count & 1 & 4 & 5 & 0.2 & 0.65 \\
\hline transfusion & & $\%$ & $8.3 \%$ & $13.3 \%$ & $11.9 \%$ & & \\
\hline & $+\mathrm{VE}$ & Count & 11 & 26 & 37 & & \\
\hline & & $\%$ & $91.7 \%$ & $86.7 \%$ & $88.1 \%$ & & \\
\hline Plasma infusion & $-\mathrm{VE}$ & Count & 1 & $\mathbf{0}$ & 1 & 2.56 & 0.11 \\
\hline & & $\%$ & $8.3 \%$ & $0.0 \%$ & $2.4 \%$ & & \\
\hline & $+\mathrm{VE}$ & Count & 11 & 30 & 41 & & \\
\hline & & $\%$ & $91.7 \%$ & $100.0 \%$ & $97.6 \%$ & & \\
\hline Dialysis & $\mathrm{NO}$ & Count & 1 & 5 & 6 & 0.48 & 0.47 \\
\hline & & $\%$ & $8.3 \%$ & $16.7 \%$ & $14.3 \%$ & & \\
\hline & YES & Count & 11 & 25 & 36 & & \\
\hline & & $\%$ & $91.7 \%$ & $83.3 \%$ & $85.7 \%$ & & \\
\hline
\end{tabular}

This table shows highly significant association between unfavorable outcome and anuria ( $\mathrm{P}$ value < 0.001). Also, there is significant association between unfavorable outcome and intractable seizures ( $\mathrm{P}$ value $<0.05$ ) and there is significant association between unfavorable outcome and positive blood culture ( $\mathrm{P}$ value $<0.05)$. However there is no significant association with other parameters. 
Table (10) showing association between diarrhea and positive stool culture.

\begin{tabular}{|c|c|c|c|c|c|c|c|}
\hline & & & Diarrhea & & Total & $\mathrm{X}^{2}$ & $\mathbf{P}$ \\
\hline & & & No & Yes & & & \\
\hline \multirow{4}{*}{$\begin{array}{l}\text { Stool } \\
\text { culture }\end{array}$} & \multirow[t]{2}{*}{$-\mathbf{V E}$} & Count & 7 & 28 & 35 & 1.68 & 0.19 \\
\hline & & $\begin{array}{l}\text { \% within } \\
\text { diarrhea }\end{array}$ & $100.0 \%$ & $80.0 \%$ & $83.3 \%$ & & \\
\hline & \multirow[t]{2}{*}{$+\mathrm{VE}$} & Count & $\mathbf{0}$ & 7 & 7 & & \\
\hline & & $\begin{array}{l}\text { \% within } \\
\text { diarrhea }\end{array}$ & $0.0 \%$ & $20.0 \%$ & $16.7 \%$ & & \\
\hline \multirow[t]{2}{*}{ Total } & & Count & 7 & 35 & 42 & & \\
\hline & & $\begin{array}{l}\text { \% within } \\
\text { diarrhea }\end{array}$ & $100.0 \%$ & $100.0 \%$ & $100.0 \%$ & & \\
\hline
\end{tabular}

This table shows that there is no significant association between diarrhea and positive stool culture ( $\mathrm{P}$ value $>0.05)$.

\section{DISCUSSION}

Hemolytic uremic syndrome (HUS) is the most common cause of acute renal failure in young children. The present study aimed to calculate the annual incidence of HUS and to observe variable clinical manifestations, laboratory abnormalities and the outcome of HUS patients. The present study was performed in a tertiary care centre at nephrology unit and intensive care unit, Children hospital, Pediatrics and Clinical Pathology departments, faculty of medicine, Zagazig University over a period of 2 years.

In the present study, we noticed that the overall incidence of hemolytic uremic syndrome of children in pediatric age group ( $<15$ years) was 1.2 per 100,000 children. Similar to our results, Noris and remuzzi observed that the overall annual incidence of HUS was 1- 2 cases per 100,000 children ${ }^{[7]}$. In our study, the annual incidence of HUS was highest below 5 years old (2.69 per 100,000 children). However HUS incidence was 0.516 per 100,000 children between 5 10 years and 0.35 per 100,000 children between 10-15 years.

Similar to our results, Tarr et al., noticed that the annual incidence of HUS was higher in young children and that age specific incidence was 3.1 per 100,000 children for Canadian children younger than five years ${ }^{[8]}$.

Tozzi et al., also reported higher incidence of hemolytic uremic syndrome in Italian children below five years (1.68 cases per 100,000 population) ${ }^{[9]}$.
Also, Elliott et al., reported HUS in Australian children younger than five years as 1.35 per 100,000 population ${ }^{[10]}$.

In the present study, we found that the majority $(57 \%)$ of the cases were younger than two years, and most of them (76\%) were below the age of five years. Similar to our results, Srivastava et al., also found that most of their patients $(59 \%)$ were younger than the age of two years and $92 \%$ of their patients were younger than five years. We also found that males patients $(74 \%)$ were more than females patients (26\%) and male to female ratio was 2.8: 1. Similar to our results, Srivastava et al., also noticed that males $(72.6 \%)$ were more affected than females and observed that male to female ratio was 2.5 : $1^{[11]}$.

However, Jodele et al., observed equal affection of males and females and reported more severe disease in female patients ${ }^{[12]}$.

In the present study, we found that the most of our cases $(79 \%)$ were detected in summer (from April to September), which is similar to other studies where the authors noticed that hemolytic uremic syndrome occurred more frequently during summer months. For example, Taylor et al., in their study reported that the incidence of HUS was higher in warmer months, especially from June to September ${ }^{[13]}$.

However, Brandt et al., reported that North West epidemic did not occur in summer ${ }^{[14]}$. Siegler and Oakes also noticed that most of their patients had oliguria and that about $50 \%$ 
of them had anuria. They also reported that convulsions occurred in $10 \%$ of patients ${ }^{[15]}$.

Chang et al., also reported that bloody stool occurred in $82 \%$ of their patients ${ }^{[16]}$.

Similar to our results, Watanabe reported severe CNS manifestations occurred in less than $20 \%$ of cases in the form of Seizures and significant encephalopathy resulting from focal ischemia due to microvascular CNS thrombosis ${ }^{[17]}$.

Weitz et al., in their study reported that $5 \%$ all HUS cases were associated with streptococcus pneumoniae infection and was manifested with pneumonia and empyema ${ }^{[18]}$. Mannucci reported congestive heart failure in $5 \%$ of hemolytic uremic syndrome patients and stated that and severe anemia, volume overload and hypertension can together precipitate heart failure ${ }^{[19]}$.

However, in contrast to our study, Brilliant et al., reported that hemolytic uremic syndrome was found without evidence of microangiopathic hemolytic anemia on blood film (peripheral blood smear) ${ }^{[20]}$.

Similar to our results, Kavanagh et al., reported hyponatremia in $86 \%$ of their patients, hypokalemia in $57 \%$ of patients and hyperkalemia $23 \%$ of patients ${ }^{[21]}$.

Tarr also reported that dilutional hyponatremia is common in HUS patients (89\%), hyperkalemia may occur $(20 \%)$ due to acute renal failure, however, unexplained significant hypokalemia is more common in most $(50 \%)$ of HUS patients (paradoxical finding in a case of acute renal failure ${ }^{[22]}$.

Similar to our results, Jha et al., in their study found positive stool culture in only $17 \%$ of their patients. The most common organisms were E coli and shigella were. However, other authors reported in their study that out of 73 patients, 27 (37\%) patients had positive stool culture positive and that the main organisms were E. coli and Shigella ${ }^{[23]}$.

Lei et al., reported that most of HUS patients $(85 \%)$ required packed RBCs transfusion ${ }^{[24]}$.

Ariceta et al., in their study, reported that daily plasma infusions have been effective in treatment of atypical HUS ${ }^{[25]}$.

Licht et al., reported that plasma therapy remains the most important line of treatment for most patients of atypical hemolytic-uremic syndrome because plasma products can replace the deficient or abnormal von Willbrand factor (vWF) metalloproteinase or complement factors ${ }^{[26]}$.

Loirat et al., recommended peritoneal dialysis for infants and young children because it is technically easier, and usually well tolerated especially in small infants ${ }^{[27]}$.

Harrison reported that hemodialysis is also suitable for children and for cases with severe abdominal pain ${ }^{[28]}$.

Some authors reported high mortality rate as $60 \%$ of cases while Siegler observed that mortality rate was between $4-10 \%{ }^{[29]}$.

In the present study, unfavorable outcome and mortality were associated with young age, high WBC count, hyperkalemia, anuria, and intractable seizures.

Similar to our results, Walters et al., (2012) observed that polymorph nuclear cell count was significantly higher in their diarrhea associated HUS patients who had a poor outcome ${ }^{[30]}$.

Also, D'Souza et al., (2009) reviewed literature and reported bad prognostic factors as younger age at presentation, leukocytosis, hyperkalemia, systemic involvement, anuria or prolonged oliguria, and prolonged convulsions ${ }^{[31]}$.

\section{CONCLUSION}

The overall incidence of hemolytic uremic syndrome of children in pediatric age group ( $<15$ years) was 1.2 per 100000 children. The annual incidence of HUS was highest below 5 years old (2.69 per 100000 children). Unfavorable outcome was associated with young age , anuria, intractable seizures, high WBC count more than 30,000 per $\mathrm{mm} 3$, and hyperkalemia above $5 \mathrm{~m} \mathrm{~mol} / \mathrm{L}$. The presence or absence of enteropathic organisms on stool culture has is not essential for diagnosis of diarrhea-associated HUS. This is because only a small number of patients infected with those organisms develops HUS, and also the organisms that cause HUS may be rapidly eliminated. Therefore the stool culture is often negative in patients who have diarrhea-associated HUS.

\section{REFERENCES}

1) Blackal DPl and Marques M. Hemolytic uremic syndrome revisited Shiga Toxin, factor $\mathrm{H}$ and fibrin generation. Am J Clin Pathol 2010; 121: S81-S88. 
2) Ray PE, and Liu XH. Pathogenesis of shiga toxin-induced hemolytic uremic syndrome Pediatr Nephrol 2007; 16: 823-839.

3) Waters AM, Kerecuk L, Luk D, et al., Hemolytic uremic syndrome associated with invasive pneumococcal disease: the United Kingdom experience. J Pediatr 2012; 151:140-144.

4) Taylor CM. Entero-hemorrhagic Escherichia coli and Shigella dysenteriae type 1-induced hemolytic uremic syndrome. Pediatr Nephrol 2012; 23: 1425-1431.

5) Walker WA. Pediatric Gastrointestinal Disease: Pathophysiology, Diagnosis, and Management. J Pediatr 2008; 113: 112-119.

6) Exeni RA, Fernandez GC, and Palermo MS. Role of polymorphonuclear leukocytes in the pathophysiology of typical hemolytic uremic syndrome. ScientificWorld J 2007; 7: 11551164.

7) Noris M, and Remuzzi G. Atypical hemolytic-uremic syndrome. N Engl J Med 2013; 361:1676-1687

8) Tarr PI, Gordon CA, and Chandler WL. Shiga-toxin-producing Escherichia coli and hemolytic uremic syndrome. Lancet 2014; 365:1073-1086.

9) Tozzi AE, Caprioli A, Minelli F et al., Shiga Toxin-Producing Escherichia coli Infections Associated with Hemolytic Uremic Syndrome, Emerging Infec Dis 2012; 9: 106 -108 .

10) Elliott EJ, Robins RM, Loughlin EV et al., Nationwide study of hemolytic uremic syndrome, clinical microbiological and epidemiological features: Arch Dis child 2012; 85: $125-131$.

11) Srivastava RN, Moudgil A, Bagga A, et al., Hemolytic uremic syndrome in children in north India. Pediatr Nephrol 2008; 5: $284-$ 288.

12) Jodele S, Davies SM, Lane A, et al., Diagnostic and risk criteria for HSCTassociated thrombotic microangiopathy: a study in children and young adults. Blood 2014; 124:645.

13) Taylor CM, Machin S, Wigmore SJ, et al., Clinical practice guidelines for the management of atypical haemolytic uraemic syndrome in the United Kingdom. $\mathrm{Br} \mathrm{J}$ Haematol 2010; 148:37.

14) Brandt JR, Fouser LS, Watkins SL, et al., Escherichia coli $\mathrm{O}$ 157: H7 associated hemolytic uremic syndrome after ingestion of contaminated hamburgers. J Pediatr 2010; 125: 519-26.
15) Siegler R, and Oakes R. Hemolytic uremic syndrome; pathogenesis, treatment, and outcome. Curr Opin Pediatr 2012;17(2):2004.

16) Chang HG, Kacica M, Smith PF, et al., Hemolytic Uremic Syndrome Incidence in New York. Emerging Infect. Dis 2010; 10: 928 -930.

17) Watanabe T. Renal complications of seasonal and pandemic influenza A virus infections. Eur J Pediatr 2013; 172:15.

18) Weitz M, Amon O, Bassler D, et al., Prophylactic eculizumab prior to kidney transplantation for atypical hemolytic uremic syndrome. Pediatr Nephrol 2011; 26(8):1325-9.

19) Mannucci PM. Thrombotic thrombocytopenic purpura and the hemolytic uremic syndrome: much progress and many remaining issues. Haematologica 2009; 92: 878-880.

20) Brilliant SE, Lester PA, Ohno AK, et al., Hemolytic uremic syndrome without evidence of microangiopathic hemolytic anemia on peripheral blood smear. South Med J 2007; 89: 342 -5.

21) Kavanagh D, Richards A, Fremeaux-Bacchi $\mathrm{V}$, et al., Screening for complement system abnormalities in patients with atypical hemolytic uremic syndrome. Clin J Am Soc Nephrol 2010; 2: 591-596.

22) Tarr PI. Shiga toxin-associated hemolytic uremic syndrome and thrombotic thrombocytopenic purpura: distinct mechanisms of pathogenesis. Kidney Int Suppl 2014; 112:S29-S32.

23) Jha DK, Singh R, Raja S, et al., Clinicolaboratory profile of hemolytic uremic syndrome. Kathmandu University Medical Journal 2010; 5:468-474

24) Lei TH, Hsia SH, Wu CT, et al., Streptococcus pneumoniae-associated hemolytic uremic syndrome following influenza A virus infection. Eur J Pediatr 2010; 169:237.

25) Ariceta G, Besbas N, Johnson $\mathrm{S}$ et al., Guideline for the investigation and initial therapy of diarrhea-negative hemolytic uremic syndrome. Pediatr Nephrol 2014; 24(4):687-696

26) Licht C, Greenbaum LA, Muus P, et al., Efficacy and safety of eculizumab in atypical hemolytic uremic syndrome from 2-year extensions of phase 2 studies. Kidney Int 2015;87 (5):1061-73.

27) Loirat C, Girma JP, Desconclois C, et al.,Thrombotic thrombocytopenic purpura 
related to severe ADAMTS13 deficiency in children. Pediatr Nephrol 2013; 24:19-29.

28) Harrison P. Early Eculizumab Treatment Improves Outcomes in Atypical Hemolytic Uremic Syndrome. Pediatr Nephrol 2015;45:627-30.

29) Siegler RL. Spectrum of extra renal involvement in post diarrheal hemolytic uremic syndrome. J Pediatr 2009; 125: 511 518.

30) Walters MDS, Matthei IV, Kay R, et al., The polymorph nuclear leukocyte count in childhood hemolytic uremic syndrome. Pediatr Nephrol 2012; 3: 130 -134.

31) D 'Souza IE, Phadke KD, and Subba SD. Atypical hemolytic uremic syndrome. Indian Pediatr 2009; 39: 162-167 